\title{
Mycotoxin Detection in Maize, Commercial Feed, and Raw Dairy Milk Samples from Assiut City, Egypt
}

\author{
Mohamed F. Abdallah 1,2,*何, Gözde Girgin ${ }^{2}$ and Terken Baydar ${ }^{2}$ \\ 1 Department of Forensic Medicine and Toxicology, Faculty of Veterinary Medicine, Assiut University, \\ Assiut 71515, Egypt \\ 2 Department of Pharmaceutical Toxicology, Faculty of Pharmacy, Hacettepe University, Sihhiye, \\ 90-06100 Ankara, Turkey; ggirgin@hacettepe.edu.tr (G.G.); tbaydar@hacettepe.edu.tr (T.B.) \\ * Correspondence: mohamed.fathi@vet.au.edu.eg
}

Received: 25 May 2019; Accepted: 14 June 2019; Published: 18 June 2019

\begin{abstract}
This survey was conducted to investigate the contamination by multiple mycotoxins, aflatoxins $\left(\mathrm{AFB}_{1}, \mathrm{AFB}_{2}, \mathrm{AFG}_{1}\right.$, and $\left.\mathrm{AFG}_{2}\right)$, ochratoxin $\mathrm{A}(\mathrm{OTA})$, and zearalenone (ZEA) in 61 samples of maize and 17 commercial animal feed samples, and of aflatoxin $\mathrm{M}_{1}\left(\mathrm{AFM}_{1}\right)$ in raw dairy milk samples $(n=20)$ collected from Assiut City in Upper Egypt. Multi-mycotoxin immunoaffinity columns were used for samples cleanup and mycotoxin purification. An HPLC-FLD system with an on-line post-column photochemical derivatization was used for the detection of the target toxins. $\mathrm{AFB}_{1}$ was detected in both maize $(n=15)$ and feed $(n=8)$, with only one maize sample presenting a concentration above the maximum permissible level set by the Egyptian authorities. $\mathrm{AFB}_{2}$ was observed in six maize samples and in one feed sample, with a maximum value of $0.5 \mu \mathrm{g} / \mathrm{kg}$. ZEA was detected only in feed samples ( $\mathrm{n}=4$ ), with a maximum value of $3.5 \mu \mathrm{g} / \mathrm{kg}$, while OTA, $\mathrm{AFG}_{1}$, and $\mathrm{AFG}_{2}$ were under the limits of detection. For milk, all the analyzed samples $(100 \%)$ were contaminated with $\mathrm{AFM}_{1}$, and 14 samples $(70 \%)$ presented concentrations above the maximum permissible level in the European Union (EU) $(0.05 \mu \mathrm{g} / \mathrm{kg})$. The concentrations ranged from $0.02 \mu \mathrm{g} / \mathrm{kg}$ to $0.19 \mu \mathrm{g} / \mathrm{kg}$, except that of one sample, which was under the limit of quantification. The contamination rates in maize and animal feeds are not alarming. In contrast, the consumption of dairy milk samples in Assiut City may pose public health hazards, as $\mathrm{AFM}_{1}$ levels were found to exceed the international permissible limits. Further surveys are highly recommended in order to establish a database for mycotoxin occurrence in Egypt to minimize the possible health risks in animals and humans.
\end{abstract}

Keywords: mycotoxins; maize; raw milk; aflatoxins; ochratoxin a; zearalenone; HPLC; Egypt

\section{Introduction}

Mycotoxins are secondary metabolites produced by different species of fungi such as Aspergillus, Penicillium, Fusarium and Alternaria [1,2]. These fungi are very diverse and can grow under a wide array of climatic conditions [3]. The diversity of mycotoxin structures induces various toxic effects in mammals, poultry, and fish. The health impacts depend on several factors such as species, age, gender, health, and physiological state of the exposed organism [4]. Some of these effects may be carcinogenic, mutagenic, teratogenic, nephrotoxic, hepatotoxic, estrogenic, hemorrhagic, neurotoxic, immunotoxic, and dermotoxic [3,5]. In addition, more than one toxic effect may occur in the case of multiple mycotoxins co-exposure, owing to their possible synergistic and/or additive effects, or in the presence of other types of natural or synthetic contaminants.

Several outbreaks were reported in humans and animals after consumption of mycotoxin-contaminated foods. Because of their serious impacts on health and worldwide economy, more than 100 countries adopted specific maximum mycotoxin limits in 2003. However, still most of the 
African countries have no specific mycotoxin regulations [6]. The absence of these regulations is mainly related to insufficient data on the occurrence of mycotoxins. Among these countries, Egypt regulates only the maximum permissible level of total AFs and $\mathrm{AFB}_{1}$ concentrations, $20 \mu \mathrm{g} / \mathrm{kg}$ and $10 \mu \mathrm{g} / \mathrm{kg}$, respectively, for both animal feed and maize [7]. Moreover, without reliable data on mycotoxins occurrence, performing assessment of exposure may not be feasible.

On the other hand, several methods have been developed in order to simultaneously detect mycotoxins in different matrices, especially maize and feeds, using HPLC coupled with a fluorescence detector (FLD) [8,9]. The literature shows that most of the previous surveys conducted in Egypt have focused on a single or a few mycotoxins in maize and/or feed using screening methods for qualitative detection. For example, thin layer chromatography (TLC) was used for the detection of total aflatoxins (AFs), aflatoxin $\mathrm{B}_{1}\left(\mathrm{AFB}_{1}\right)$, and zearalenone (ZEA) in maize by El-Tahan et al., 2000 [10], El-Gohary, 1995 [11], and Abd Alla, 1997 [12], respectively. Total AFs in feedstuffs [13] and fumonisins in maize [14] from Assiut City were surveyed using ELISA. Ochratoxin A (OTA) was rarely investigated in Egypt. Because of the absence of sufficient and up-to-date surveys on mycotoxin contamination in Egypt, especially in the upper (south) part of the country, the aim of the present work was to survey the natural occurrence of three classes of the most researched mycotoxins worldwide, i.e., AFs, OTA, and ZEA in maize and commercial feed marketed in Assiut, Egypt. In addition, $\mathrm{AFM}_{1}$ in raw dairy milk samples from the same area was also analyzed.

\section{Materials and Methods}

\subsection{Sample Collection}

All samples, maize $(n=61)$ and commercial animal feed $(n=17)$, were randomly collected between summer 2014 and winter 2015 ( $250 \mathrm{~g}$ each) from generic local markets as well as from farms located across Assiut Governorate in Upper Egypt. In addition, 20 raw cow milk samples ( $250 \mathrm{~mL}$ each) intended for human consumption were purchased from different local markets in the same area during the summer season of 2014. The identities of markets, local vendors of raw milk, and commercial manufacturers of feeds and maize cannot be disclosed because of the confidential nature of this information. The samples were transported in polystyrene boxes with a cooling gel (pre-frozen to $-20^{\circ} \mathrm{C}$ ) to Ankara, Turkey, for extraction and mycotoxin quantification using HPLC-FLD. All samples were stored at $-20^{\circ} \mathrm{C}$ until the time of analysis.

\subsection{Sample Preparation and Extraction}

\subsubsection{Maize and Animal Feed Samples}

Each sample ( $250 \mathrm{~g})$ of maize and feed was ground by using a laboratory blender (Osterizer ${ }^{\circledR}$ Blender, Waring commercial, Cheadle, UK) at high speed for 1-2 min. Sample extraction was done according to the instructions of the manufacturer and as published by Göbel and Lusky (2004) [15]. Each sample $(25 \mathrm{~g})$ was mixed with $5 \mathrm{~g}$ of sodium chloride in $100 \mathrm{~mL}$ of acetonitrile and purified water $(80: 20, v / v)$ and blended for $2 \mathrm{~min}$ at high speed. The mixture was filtered by fluted filter paper (Vicam, Nixa, MO, USA), and $10 \mathrm{~mL}$ of the extract was diluted with $40 \mathrm{~mL}$ of phosphate-buffered saline (PBS) ( $\mathrm{pH}$ 7.4) containing $0.01 \%$ Tween 20 . The mixture was vortexed, and a second filtration was performed using a microfiber filter paper (Vicam, Nixa, MO, USA). An aliquot of $20 \mathrm{~mL}$ of the filtrate was passed through a multiple-mycotoxin immunoaffinity columns (AOZ IAC) purchased from Vicam (Nixa, MO, USA), by a syringe barrel, at a flow rate of 1-2 drops/second. The column were washed with $10 \mathrm{~mL}$ PBS containing $0.01 \%$ Tween 20 followed by $10 \mathrm{~mL}$ of purified water. The IAC columns were dried gently by passing air for 2-3 s and then washed with purified water. The target toxins were eluted from the IAC columns by passing $1.5 \mathrm{~mL}$ of methanol (Sigma, Darmstadt, Germany) and $1.5 \mathrm{~mL} 0.1 \%$ acetic acid (Sigma, Germany) and collected in one glass tube. After vortexing, the final mixture was transferred into HPLC injection vials and subjected to analysis. 


\subsubsection{Dairy Milk Samples Extraction}

$\mathrm{AFM}_{1}$ extraction and detection was done according to the protocol published by Dragacci et al. (2001) [16]. Each raw milk sample (250 mL) was centrifuged at 3190 RCF (Hettich Universal Rotina 420 R, Germany) for $15 \mathrm{~min}$ at room temperature (RT) to get rid of the fatty layer. Afterwards, the samples were filtered through fluted filter paper (Vicam, Nixa, MO, USA) and microfiber filter paper (Vicam, Nixa, MO, USA). The skimmed milk samples (each $50 \mathrm{~mL}$ ) were loaded by a syringe barrel Afla $\mathrm{M}_{1}$ immunoaffinity columns (Vicam, Nixa, MO, USA) at a rate of 1-2 drops/second. The columns were washed twice with $10 \mathrm{~mL}$ of purified water at a rate of 1-2 drops/second to get rid of impurities, and the toxin was eluted from the column by passing $1.25 \mathrm{~mL}$ of a solution of acetonitrile/methanol $(3: 2, v / v)$ at a rate of 1 drop for every $2-3 \mathrm{~s}$, followed by an equal amount of purified water. The final solution was collected in a glass cuvette and transferred into HPLC injection vials for analysis.

\subsubsection{HPLC Parameters for Multi-Mycotoxin and $\mathrm{AFM}_{1}$}

The chromatographic parameters for the analysis are described in Ofitserova et al. (2009) [9]. Chromatographic separation was performed by using an Agilent 1100 HPLC equipped with an ACE ${ }^{\circledR}$ C18 column $(25 \mathrm{~cm} \times 4.6 \mathrm{~mm}$, particle size $5 \mu \mathrm{m})$ and a C18 $4 \times 3 \mathrm{~mm}$ i.d. security guard cartridge (Aberdeen, Scotland). The HPLC device was coupled with a fluorescence detector for quantitative determination with on-line post column photochemical derivatization. The photochemical reactor (Vicam, Nixa, MO, USA) was used for aflatoxins $\left(\mathrm{AFB}_{1}\right.$ and $\left.\mathrm{AFG}_{1}\right)$ to enhance the sensitivity and/or selectivity of the fluorescence detection response avoiding a decrease of sensitivity to $\mathrm{AFB}_{2}$ and $\mathrm{AFG}_{2}$, ZEA and OTA. The flow rate was set at $0.8 \mathrm{~mL} / \mathrm{min}$, and the column temperature at $40{ }^{\circ} \mathrm{C}$. The injection volume was $100 \mu \mathrm{L}$, and the total running time was $50 \mathrm{~min}$ including $10 \mathrm{~min}$ for equilibration. Figure 1 shows a chromatogram of a standard mix solution containing the six analytes.
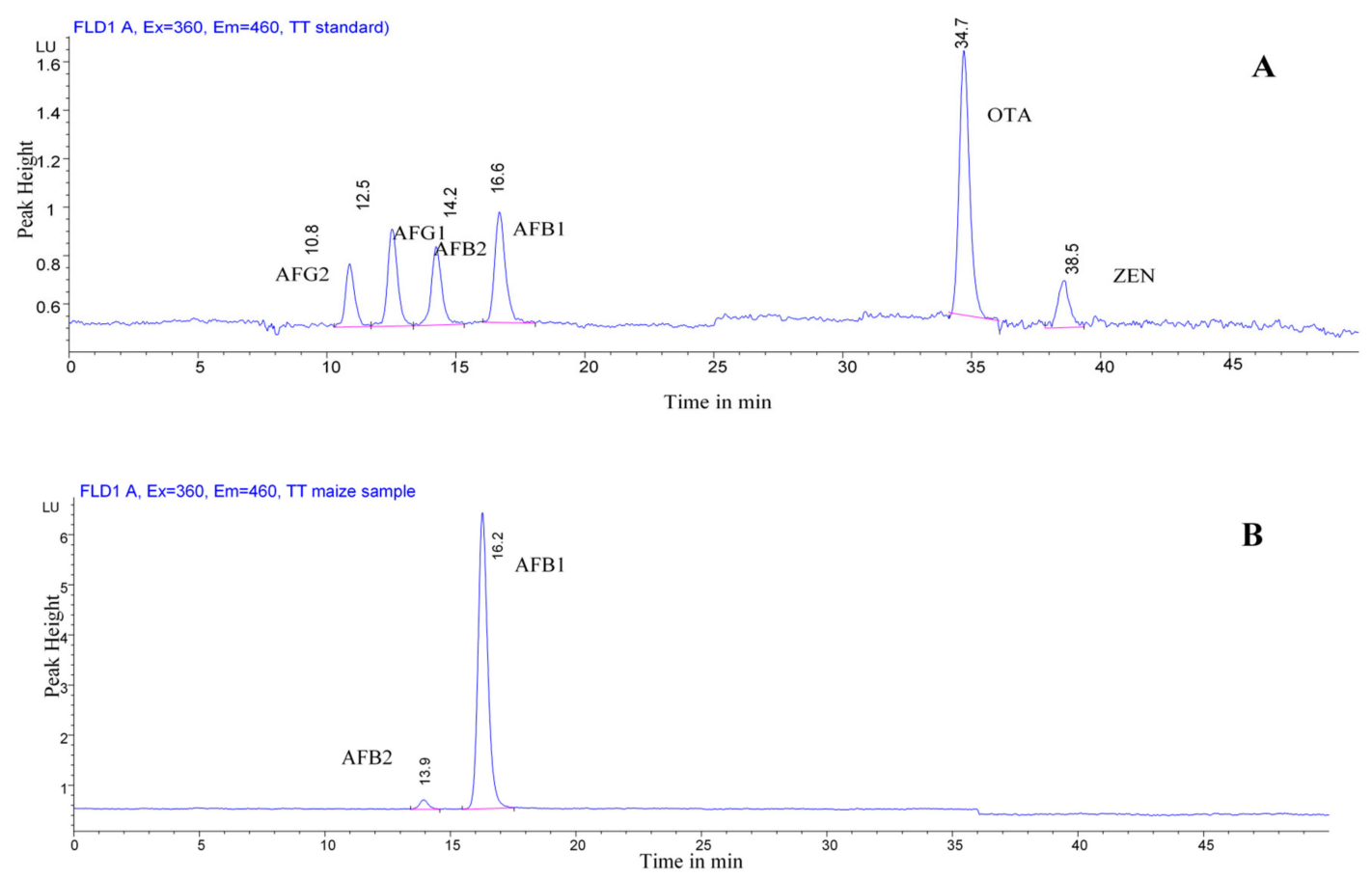

Figure 1. HPLC-fluorescence detector (FLD) chromatograms of a standard aflatoxin (AF) mixture (A) and a maize sample contaminated with $\mathrm{AFB}_{1}$ and $\left.\mathrm{AFB}_{2}\right)(\mathbf{B})$.

For $\mathrm{AFM}_{1}$, the chromatographic separation was performed at $25 \pm 1{ }^{\circ} \mathrm{C}$ using HPLC equipped with a Hichram ${ }^{\circledR}$ ODS2 column $(250 \mathrm{~mm} \times 4.6 \mathrm{~mm}$ i.d., $5 \mu \mathrm{m}$ particle size $)$ and C18 $(4 \times 3 \mathrm{~mm}$ i.d. $)$ security guard cartridge. The mobile phase consisted of methanol/water/acetonitrile $(22: 62: 16 ; v / v / v)$ in 
isocratic elution. The fluorescence detector was adjusted with excitation and emission wavelengths of $360 \mathrm{~nm}$ and $430 \mathrm{~nm}$, respectively. The injection volume was $100 \mu \mathrm{L}$. The flow rate was $1 \mathrm{~mL} / \mathrm{min}$, the retention time was $10.7 \pm 0.2 \mathrm{~min}$, and the running time was $15 \mathrm{~min}$. An HPLC chromatogram for the $\mathrm{AFM}_{1}(0.2 \mu \mathrm{g} / \mathrm{kg})$ standard solution is shown in Figure 2.
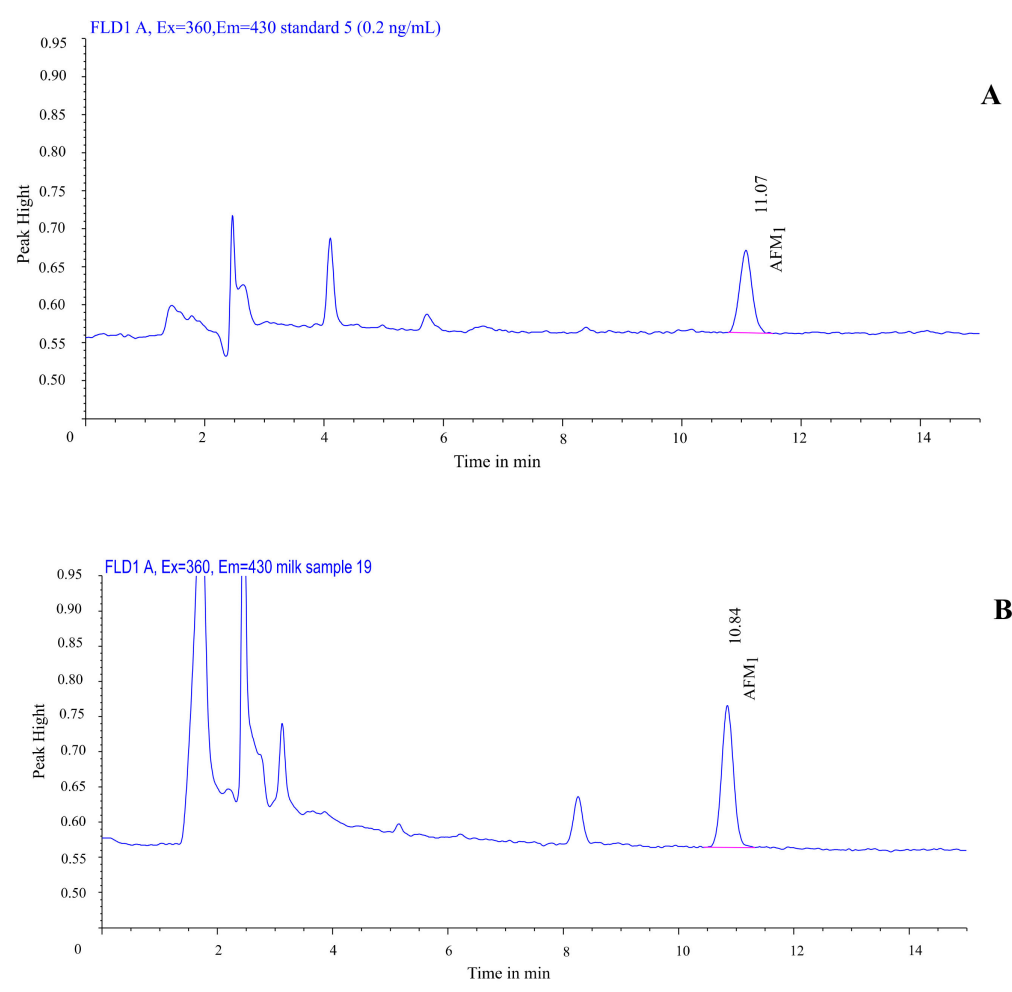

Figure 2. HPLC-FLD chromatograms of a standard solution (A) and a milk sample contaminated with aflatoxin $\mathrm{M}_{1}(\mathbf{B})$.

The sensitivity of the method was tested by examining both limit of detection (LOD) and limit of quantification (LOQ). LOD was calculated based on signal to noise ( $\mathrm{S} / \mathrm{N}=3$ ) while LOQ was $(\mathrm{S} / \mathrm{N}=10)$. LOD values were $0.92 \mu \mathrm{g} / \mathrm{kg}$ for ZEA, $0.02 \mu \mathrm{g} / \mathrm{kg}$ for OTA and varied from 0.04 to $0.12 \mu \mathrm{g} / \mathrm{kg}$ for aflatoxins. LOQ values were $2.8 \mu \mathrm{g} / \mathrm{kg}$ for ZEA, $0.06 \mu \mathrm{g} / \mathrm{kg}$ for OTA, and from 0.12 to $0.39 \mu \mathrm{g} / \mathrm{kg}$ for aflatoxins. The efficacy of the analytical method was determined by estimation of apparent recovery. The mean apparent recoveries ranged from 81 to $110 \%$ for different concentrations (cut of the calibration curve) of the target mycotoxins (Tables 1 and 2) in two spiked samples of maize and feed. For AFM 1 , LOD and LOQ values were $0.008 \mu \mathrm{g} / \mathrm{kg}$ and $0.02 \mu \mathrm{g} / \mathrm{kg}$, respectively. The recovery was performed once and was $100 \%$.

Table 1. Overview of mycotoxin contents $(\mu \mathrm{g} / \mathrm{kg})$ in feed samples.

\begin{tabular}{cccccc}
\hline Mycotoxin & N (P) & $\begin{array}{c}\text { Range } \\
\text { (Min-Max) }\end{array}$ & Median & Mean & Recovery (\%) \\
\hline $\mathrm{AFB}_{1}$ & $8(47 \%)$ & $(0.1-5.9)$ & 0.7 & 1.5 & 110 \\
\hline $\mathrm{AFB}_{2}$ & $1(6 \%)$ & $(0.5)$ & 0.5 & 0.5 & 81 \\
\hline $\mathrm{AFG}_{1}$ & n.d & n.d & n.d & n.d & 79 \\
\hline $\mathrm{AFG}_{2}$ & n.d & n.d & n.d & n.d & 80 \\
\hline $\mathrm{OTA}$ & n.d & n.d & n.d & n.d & 95 \\
\hline ZEA & $4(24 \%)$ & $(1.0-11.9)$ & 8.4 & 8.1 & 88.8 \\
\hline
\end{tabular}

$\mathrm{N} / \mathrm{P}$, number of the contaminated samples over the percentage, OTA, ochratoxin A, ZEA, zearalenone, n.d, not determined. Median and mean values were calculated for the contaminated samples. 
Table 2. Overview of mycotoxin contents $(\mu \mathrm{g} / \mathrm{kg})$ in maize samples.

\begin{tabular}{|c|c|c|c|c|c|}
\hline Mycotoxin & $\mathbf{N}(\mathbf{P})$ & $\begin{array}{c}\text { Range } \\
\text { (Min-Max) }\end{array}$ & Median & Mean & Recovery (\%) \\
\hline $\mathrm{AFB}_{1}$ & $15(25 \%)$ & $(0.2-44.9)$ & 1.35 & 8.7 & 100 \\
\hline $\mathrm{AFB}_{2}$ & $6(10 \%)$ & $(0.1-7.0)$ & 1.7 & 2.2 & 81 \\
\hline $\mathrm{AFG}_{1}$ & n.d & n.d & n.d & n.d & 84 \\
\hline $\mathrm{AFG}_{2}$ & n.d & n.d & n.d & n.d & 80.5 \\
\hline OTA & n.d & n.d & n.d & n.d & 100 \\
\hline ZEA & n.d & n.d & n.d & n.d & 85 \\
\hline
\end{tabular}

\section{Results and Discussion}

\subsection{Occurrence of Mycotoxins in Maize and Animal Feed Samples}

During the past few years, the simultaneous determination of several toxins in one analytical run was developed with the aim of reducing time and cost of the analysis and to get a better evidence of multi-mycotoxin occurrence in agriculture commodities $[9,15,17]$. HPLC has proved to be a powerful tool for mycotoxin detection and quantification. Cereals, especially maize and its products, are important agricultural commodities for feeding humans and animals. However, they can also pose risks to health if they are contaminated with mycotoxins. In fact, it is estimated that up to $100 \%$ of crops are contaminated by one mycotoxin at a low level [18].

In both feed and maize samples $(n=78)$, the most prevalent mycotoxin was $\mathrm{AFB}_{1}$. In total, 23 feed and maize samples were contaminated with $\mathrm{AFB}_{1}, 7$ samples with $\mathrm{AFB}_{2}$, and 4 samples with ZEA. Regarding feeds, $47 \%(n=8)$ of the samples were contaminated with $\mathrm{AFB}_{1}$, while $23 \%$ of maize samples $(n=15)$ were contaminated with for $A_{F B}$. Also, the maximum level of $A_{F B}$ in feed was much lower than that detected in maize. ZEA was detected only in feed samples, while OTA, AFG 1 , and $\mathrm{AFG}_{2}$ were not detected in either matrix. The prevalence, mean, and median values are presented in Tables 1 and 2.

AFs are mainly produced by several species of Aspergillus section Flavi [3,4]. The four types of AFs $\left(B_{1}, B_{2}, G_{1}\right.$, and $\left.G_{2}\right)$ are ubiquitous in food and feed stuffs and contaminate many commodities including peanuts, rice, maize, cottonseed, almonds, spices, sugarcane, palm dates [19], and figs [17,20-22]. AFs are by far the most intensively researched toxins due to their potent acute toxicity and chronic hepatocarcinogenic effects in various susceptible animal species. Although the liver is the primary target organ, under certain conditions, lung, kidney, and colon may be also affected [1,4,23]. The International Agency for Research on Cancer (IARC) has classified aflatoxin $B_{1}$ and naturally occurring mixtures of aflatoxins as human carcinogens (group 1) [24]. The highest incidence of hepatocellular carcinoma occurs in areas where people are frequently exposed to contaminated food and have a high rate of infection with hepatitis, such as Eastern and South Eastern Asia and Middle and Western Africa $[3,21]$.

Our results confirmed the presence of $\mathrm{AFB}_{1}$ in maize from Egypt at levels higher than the national and international limits. This data are also in agreement with the previous reported levels in maize from Cairo $(19.2 \mu \mathrm{g} / \mathrm{kg}$ ) [25] and from Assiut $(21.8 \mu \mathrm{g} / \mathrm{kg})$ [26]. AFB 1 level in feed was lower than those reported in feedstuff from different regions of Egypt, where up to $400 \mu \mathrm{g} / \mathrm{kg}$ were detected, [27] and from Assiut, where $60 \mu \mathrm{g} / \mathrm{kg}$ were detected [13].

OTA is the most commonly encountered and toxic metabolite of the ochratoxin group. The metabolite is a fluorescent secondary metabolite produced by two genera of fungi, Aspergillus and Penicillium [4]. The toxin is a frequent natural contaminant in food, including various cereal products, coffee, spices, bean, as well as dried fruits, grapes, and grape-based products such as wine. Moreover, 
edible animal tissues and milk were reported to be contaminated with OTA $[5,28]$. The main target organ involved in OTA toxicity is the kidney, and the toxin may have some carcinogenic, genotoxic, immunotoxic, and potent nephrotoxic effects. In the Balkan countries, OTA has been linked to a high incidence of urinary tract carcinomas, a condition known as Balkan Endemic Nephropathy $[1,3]$. OTA has been classified by IARC as a possible carcinogen to humans (group 2B). OTA is not a frequent food and feed contaminant in Egypt, as confirmed by a recent survey from Upper Egypt, where the authors screened for a wide range of fungal metabolites in animal feed and maize but could not detect OTA [17].

ZEA is a mycotoxin with hyperestrogenic effects produced by Fusaria, mainly Fusaria graminearum, Fusaria culmorum, and Fusaria cerealis. The toxin is a frequent contaminant of several cereal crops worldwide, especially maize [5]. ZEA resembles $17 \beta$-estradiol and is classified as a non-steroidal oestrogenic mycotoxin, which causes mainly reproductive problems in domestic farm animals, especially swine. The toxin is also suspected to cause precocious puberty in humans. ZEA is considered not classifiable with regard to its carcinogenicity in humans (group 3) [24]. The level of ZEA detected in the present study was much lower than those detected in feed $(791 \mu \mathrm{g} / \mathrm{kg})$ and maize $(184 \mu \mathrm{g} / \mathrm{kg})$ from upper Egypt [17], which reached the maximum values; however, the measured level was higher than those reported for maize in Cairo $(2.15 \mu \mathrm{g} / \mathrm{kg}$ ) [29], in some Egyptian districts (45.2 $\mu \mathrm{g} / \mathrm{kg})$ [12], and in other surveys $(3.5 \mu \mathrm{g} / \mathrm{kg})[26,27]$. Until now, there are no regulations for ZEA in any commodity in Egypt, and extensive surveys on different food and feed commodities should be conducted to gain more information about ZEA occurrence and the fungi that produce it in the Egyptian environment.

\subsection{Occurrence of $A F M_{1}$ in Dairy Raw Samples}

The analysis using a reversed-phase liquid chromatography coupled with a fluorescence detector showed that all the examined milk samples were contaminated with $\mathrm{AFM}_{1}$. Among them, 14 samples (70\%) presented concentrations above the maximum permissible level set by the EU $(0.05 \mu \mathrm{g} / \mathrm{kg})$ (EC, 2010). The detected concentrations in the samples ranged from $0.02 \mu \mathrm{g} / \mathrm{kg}$ to $0.19 \mu \mathrm{g} / \mathrm{kg}$, except for only one sample whose concentration was under the LOQ. Figure 2 shows a chromatogram of a $0.2 \mu \mathrm{g} / \mathrm{kg} \mathrm{AFM}{ }_{1}$ standard and a naturally contaminated milk sample, containing $0.19 \mu \mathrm{g} / \mathrm{kg} \mathrm{AFM}$.

Milk is a natural nutritious food for humans, especially for children. However, it also serves as a favorable environment for the growth of various microorganisms, and can be contaminated with other toxins through carry over from the dairy animals.

$\mathrm{AFM}_{1}$, the hydroxylated metabolic form of $\mathrm{AFB}_{1}$, is present in dairy milk of animals that ingested feedstuffs contaminated with $\mathrm{AFB}_{1}$ [28]. $\mathrm{AFM}_{1}$ is classified as a possible human carcinogen in Group $2 \mathrm{~B}$, as its carcinogenicity is 10 times less than that of the parent compound [24].

In general, the presence of $\mathrm{AFM}_{1}$ in milk depends exclusively on the absorbed concentrations of the precursor $\mathrm{AFB}_{1}$ in animal feeds. It has been estimated that around $5 \%$ of digested $\mathrm{AFB}_{1}$ is converted and excreted into the milk of dairy animals [1,5,30]. However, the amount of excreted $\mathrm{AFM}_{1}$ is subjected to individual variation in addition to a seasonal variation, according to the nature of feed in summer and winter. It has been reported that $\mathrm{AFM}_{1}$ can be detected after $12 \mathrm{~h}$ from the time of ingestion of $\mathrm{AFB}_{1}$-contaminated forages or animal concentrates by lactating dairy animals, and its level decreases gradually, becoming mostly undetectable within $72 \mathrm{~h}$ after the removal of $\mathrm{AFB}_{1}$-contaminated feeds. Also, the unsanitary conditions and/or contamination of the utensils used for milking or inside local markets for handling and boiling the raw milk might contribute to milk contamination with the toxin [31]. The toxin is not totally destroyed by pasteurization, autoclaving, and other food-processing procedures [32]. Yet, little is known about the natural occurrence of $\mathrm{AFM}_{1}$ in dairy products in Egypt. The determined levels of $\mathrm{AFM}_{1}$ observed in the present study $(0.02-0.19 \mu \mathrm{g} / \mathrm{kg})$ were lower than those reported previously from different districts of Egypt. For example, a very high level of contamination was reported $(5-8 \mu \mathrm{g} / \mathrm{kg})$ in 3 cow milk samples out of 15 samples collected from Cairo and Giza Governorates, using HPLC-FLD [31]. In another survey conducted in Ismailia Governorate, $0.01-0.2 \mu \mathrm{g} / \mathrm{kg}$ of $\mathrm{AFM}_{1}$ was detected in 50 samples of cow milk, using ELISA [32], and 
in a recent survey from Assiut Governorate, the $\mathrm{AFM}_{1}$ level detected was 0.09-0.5 $\mu \mathrm{g} / \mathrm{kg}$, again using ELISA [33].

On the other hand, Salem 2002 [13] reported up to $0.015 \mu \mathrm{g} / \mathrm{kg}$ of $\mathrm{AFM}_{1}$ in milk samples from Assiut Governorates using ELISA, and Ghareeb et al. (2013) [30] found the same prevalence of AFM in 48 raw milk samples (97.92\%), with a concentration up to $0.11 \mu \mathrm{g} / \mathrm{kg}$ from Qena Governorates, using the same technique. The current results are generally in agreement with those of previous reports and reveal a serious public health problem for the Egyptian population living in Assiut Governorate, as it is exposed to $\mathrm{AFM}_{1}$ levels above the international limits. In most of the developing countries, including Egypt, raw milk is sold without or with a minimal traditional heat treatment that, in fact, does not affect mycotoxins and their metabolites, as they are in general heat-resistant. Because of the lack of data on the natural occurrence of AFs and other factors such as lack of laboratory analytical equipment, no official regulation has been established by the Egyptian authorities so far. Also, it should be kept in mind that the total daily aflatoxin and other mycotoxins intake from other types of food could be an additional important risk factor.

\section{Conclusions}

The present study presents the occurrence of multiple mycotoxins in maize and animal feed from Egypt using reversed-phase liquid chromatography coupled with a fluorescence detector. The results show that the mycotoxin contamination rates are not alarming for $\mathrm{AFB}_{1}$ in maize and animal feeds, according to the international standards. Also, the concentrations of $\mathrm{AFB}_{1}$ were below the authorized levels in these food samples. In contrast, the concentrations of $\mathrm{AFM}_{1}$ in most of the analyzed milk samples were above the international permissible level, and therefore, the consumption of dairy milk in Assiut City may pose a public health hazard. Further and permanent monitoring is highly recommended to establish a mycotoxin occurrence database. A stricter regulation for mycotoxin levels in food should be applied in Egypt in order to control mycotoxin and their producing fungi in animal feed, maize, and other food commodities. Furthermore, reducing the maximum level of the regulated mycotoxins to a level accepted by the international standards is important to ensure consumers' safety and facilitate worldwide trade.

Author Contributions: Conceptualization, M.F.A., G.G., and T.B.; methodology, M.F.A.; writing—original draft preparation, M.F.A.; writing-review and editing, M.F.A., G.G., and T.B.; funding acquisition, G.G., and T.B.

Funding: This study was supported by Hacettepe University Research Projects Unit (014 D06 301 002-620).

Acknowledgments: The authors thank the Turkish Government Scholarships (Turkyie Burslari) for granting Mohamed F. Abdallah a fully funded master scholarship at Hacettepe University, Turkey.

Conflicts of Interest: The authors declare no conflict of interest.

\section{References}

1. Hussein, H.S.; Brasel, J.M. Toxicity, metabolism, and impact of mycotoxins on humans and animals. Toxicology 2001, 167, 101-134. [CrossRef]

2. Kovač, M.; Šubarić, D.; Bulaić, M.; Kovač, T.; Šarkanj, B. Yesterday masked, today modified; what do mycotoxins bring next? Arch. Ind. Hyg. Toxicol. 2018, 69, 196-214. [CrossRef] [PubMed]

3. Marin, S.; Ramos, A.J.; Cano-Sancho, G.; Sanchis, V. Mycotoxins: Occurrence, toxicology, and exposure assessment. Food Chem. Toxicol. 2013, 60, 218-237. [CrossRef] [PubMed]

4. Zain, M.E. Impact of mycotoxins on humans and animals. J. Saudi Chem. Soc. 2011, 15, 129-144. [CrossRef]

5. Da Rocha, M.E.; Freire, F.D.; Maia, F.E.; Guedes, M.I.; Rondina, D. Mycotoxins and their effects on human and animal health. Food Control 2014, 36, 159-165. [CrossRef]

6. Van Egmond, H.P.; Schothorst, R.C.; Jonker, M.A. Regulations relating to mycotoxins in food. Anal. Bioanal. Chem. 2007, 389, 147-157. [CrossRef] [PubMed]

7. Food and Agriculture Organization (FAO) of the United Nations Worldwide regulations for mycotoxins in food and feed in 2003. FAO Food Nutr. Pap. 2004, 81, 9-28. 
8. Rahmani, A.; Jinap, S.; Soleimany, F. Validation of the procedure for the simultaneous determination of aflatoxins ochratoxin a and zearalenone in cereals using HPLC-FLD. Food Addit. Contam. Part A 2010, 27, 1683-1693. [CrossRef] [PubMed]

9. Ofitserova, M.; Nerkar, S.; Pickering, M.; Torma, L.; Thiex, N. Multiresidue mycotoxin analysis in corn grain by column high-performance liquid chromatography with postcolumn photochemical and chemical derivatization: Single-laboratory validation. J. AOAC Int. 2009, 92, 15-25.

10. El-Tahan, F.H.; El-Tahan, M.H.; Shebl, M.A. Occurrence of aflatoxins in cereal grains from four Egyptian governorates. Nahrung Food 2000, 44, 279-280. [CrossRef]

11. El-Gohary, A.H. Study on aflatoxins in some foodstuffs with special reference to public health hazard in Egypt. Asian Australas. J. Anim. Sci. 1995, 8, 571-575. [CrossRef]

12. Abd Alla, E.S. Zearalenone: Incidence, toxigenic fungi and chemical decontamination in Egyptian cereals. Nahrung Food 1997, 41, 362-365. [CrossRef] [PubMed]

13. Salem, D.A. Natural Occurance of Aflatoxins in Feedstuffs and Milk of Dairy Farms in Assiut Porvince, Egypt. Wien. Tierarztl. Mon. 2002, 89, 86-91.

14. Salem, D.A.; Ramadan, B.R. Occurrence of fumonisins in corn, wheat and some of their based-food products in Egypt. Assiut Med. J. 2009, 33, 147-158.

15. Göbel, R.; Lusky, K. Simultaneous determination of aflatoxins, ochratoxin A, and zearalenone in grains by new immunoaffinity column/liquid chromatography. J. AOAC Int. 2004, 87, 411-416. [PubMed]

16. Dragacci, S.; Grosso, F.; Gilbert, J. Immunoaffinity column cleanup with liquid chromatography for determination of aflatoxin M1 in liquid milk: Collaborative study. J. AOAC Int. 2001, 84, 437-443. [PubMed]

17. Abdallah, M.F.; Girgin, G.; Baydar, T.; Krska, R.; Sulyok, M. Occurrence of multiple mycotoxins and other fungal metabolites in animal feed and maize samples from Egypt using LC-MS/MS. J. Sci. Food Agric. 2017, 97, 4419-4428. [CrossRef]

18. Abia, W.A.; Warth, B.; Ezekiel, C.N.; Sarkanj, B.; Turner, P.C.; Marko, D.; Krska, R.; Sulyok, M. Uncommon toxic microbial metabolite patterns in traditionally home-processed maize dish (fufu) consumed in rural Cameroon. Food Chem. Toxicol. 2017, 107, 10-19. [CrossRef]

19. Abdallah, M.F.; Krska, R.; Sulyok, M. Occurrence of ochratoxins, fumonisin $B_{2}$, Aflatoxins $\left(B_{1}\right.$ and $\left.B_{2}\right)$, and other secondary fungal metabolites in dried date palm fruits from Egypt: A mini-survey. J. Food Sci. 2018, 83, 559-564. [CrossRef]

20. Abdallah, M.F.; Krska, R.; Sulyok, M. Mycotoxin contamination in sugarcane grass and juice: First report on detection of multiple mycotoxins and exposure assessment for aflatoxins B1 and G1 in Humans. Toxins 2016, 8, 343. [CrossRef]

21. Binder, E.M.; Tan, L.M.; Chin, L.J.; Handl, J.; Richard, J. Worldwide occurrence of mycotoxins in commodities, feeds and feed ingredients. Anim. Feed Sci. Technol. 2007, 137, 265-282. [CrossRef]

22. Petrić, J.; Šarkanj, B.; Mujić, I.; Mujić, A.; Sulyok, M.; Krska, R.; Šubarić, D.; Jokić, S. Effect of pretreatments on mycotoxin profiles and levels in dried figs. Arch. Ind. Hyg. Toxicol. 2018, 69, 328-333. [CrossRef] [PubMed]

23. Kovač, T.; Šarkanj, B.; Crevar, B.; Kovač, M.; Lončarić, A.; Strelec, I.; Ezekiel, C.N.; Sulyok, M.; Krska, R. Aspergillus flavus NRRL 3251 growth, oxidative status, and aflatoxins production ability in vitro under different illumination regimes. Toxins 2018, 10, 528. [CrossRef] [PubMed]

24. IARC. Some Traditional Herbal Medicines, Some Mycotoxins, Naphthalene and Styrene. Monogr. Eval. Carcinog. Risks Hum. 2002, 82, 301-366.

25. Madbouly, A.K.; Ibrahim, M.I.M.; Sehab, A.F.; Abdel-Wahhab, M.A. Co-occurrence of mycoflora, aflatoxins and fumonisins in maize and rice seeds from markets of different districts in Cairo, Egypt. Food Addit. Contam. Part B 2012, 5, 112-120. [CrossRef] [PubMed]

26. Nooh, A.; Hassan, A.; Youssef, M.M.; El-banna, A.A. Mycotoxin and toxigenic fungi occurrence in egyptian maize. Int. J. Adv. Res. 2014, 2, 521-531.

27. Abdelhamid, A.M. Occurrence of some mycotoxins (aflatoxin, ochratoxin A, citrinin, zearalenone and vomitoxin) in various Egyptian feeds. Arch. Anim. Nutr. 1990, 40, 647-664. [CrossRef]

28. Abdallah, M.F.; Girgin, G.; Baydar, T. Occurrence, prevention and limitation of mycotoxins in feeds. Anim. Nutr. Feed Technol. 2015, 15, 471-490. [CrossRef]

29. El-Desouky, T.A.; Naguib, K. Occurrence of zearalenone contamination in some cereals in Egypt. J. Agroaliment. Process. Technol. 2013, 19, 445-450. 
30. Ghareeb, K.; Elmalt, L.M.; Awad, W.A.; Böhm, J.; Health, V.P.; Medicine, V.; Medicine, F.; Animals, F. Prevalence of Aflatoxin M 1 in Raw Milk Produced in Tropical State (Qena, Egypt) and Imported Milk Powder Sampling of milk. J. Vet. Anim. Sci. 2013, 3, 1-4.

31. Alla, A.E.; Neamat-Allah, A.A.; Aly, S.E. Situation of mycotoxins in milk, dairy products and human milk in Egypt. Mycotoxin Res. 2000, 16, 91-100. [CrossRef] [PubMed]

32. Motawee, M.M.; Bauer, J.; McMahon, D.J. Survey of Aflatoxin M1in Cow, Goat, Buffalo and Camel Milks in Ismailia-Egypt. Bull. Environ. Contam. Toxicol. 2009, 83, 766-769. [CrossRef] [PubMed]

33. Shaker, E.; Elsharkawy, E. Occurrence and the level of contamination of aflatoxin M1in raw, pasteurized, and UHT buffalo milk consumed in Sohag and Assiut, Upper Egypt. J. Environ. Occup. Sci. 2014, 3, 136-140. [CrossRef]

(C) 2019 by the authors. Licensee MDPI, Basel, Switzerland. This article is an open access article distributed under the terms and conditions of the Creative Commons Attribution (CC BY) license (http://creativecommons.org/licenses/by/4.0/). 